\title{
A Novel GPS Patch Antenna on a Fractal Hi-Impedance Surface Substrate
}

Xiulong Bao

Technological University Dublin, xiulong.bao@tudublin.ie

Giuseppe Ruvio

Technological University Dublin

Max Ammann

Technological University Dublin, max.ammann@tudublin.ie

See next page for additional authors

Follow this and additional works at: https://arrow.tudublin.ie/engscheceart

Part of the Electrical and Computer Engineering Commons

\section{Recommended Citation}

Bao, X. et al. (2006) A novel GPS patch antenna on a fractal Hi-Impedance surface substrate. IEEE Antennas and Wireless Propagation Letters, 2006, Vol.5, no. 1, pp.323-326. doi:10.1109/ LAWP.2006.878900

This Article is brought to you for free and open access by the School of Electrical and Electronic Engineering at ARROW@TU Dublin. It has been accepted for inclusion in Articles by an authorized administrator of ARROW@TU Dublin. For more information, please contact arrow.admin@tudublin.ie, aisling.coyne@tudublin.ie, gerard.connolly@tudublin.ie.

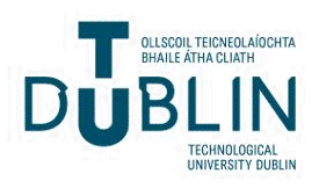




\section{Authors}

Xiulong Bao, Giuseppe Ruvio, Max Ammann, and Matthias John

This article is available at ARROW@TU Dublin: https://arrow.tudublin.ie/engscheceart/23 


\title{
A Novel GPS Patch Antenna on a Fractal Hi-Impedance Surface Substrate
}

\author{
X. L. Bao, G. Ruvio, M. J. Ammann, and M. John
}

\begin{abstract}
A compact high-performance circularly-polarized microstrip antenna for the global positioning system application is proposed. It comprises a fractal hi-impedance surface electromagnetic bandgap (EBG) structure printed on a high permittivity substrate. Measurements and simulation of return loss and axial ratio are in good agreement. It is shown that the proposed Global Positioning System antenna has good axial ratio performance in the upper half-plane, an improvement in gain and a significantly wider axial ratio bandwidth when compared to the same antenna without EBG.
\end{abstract}

Index Terms-Axial ratio, fractal hi-impedance surface, Global Positioning System (GPS) antennas.

\section{INTRODUCTION}

$\mathbf{M}$ ICROSTRIP patch antennas have been rapidly developing for the last three decades. They are used in many applications because of their low-profile, lightweight, ease of fabrication and low-cost [1]-[3]. Circularly polarized patch antennas are often used for Global Positioning System (GPS) applications, where miniaturization and high performance are required [4]. Miniaturization and performance are difficult to achieve simultaneously, particularly at lower frequencies. Some studies have been reported, which improve the performance of patch antennas using periodic structures [5], [6]. In fact, it is well-known that a patch antenna on a high dielectric constant substrate is a highly inefficient radiator due to surface wave losses and has a very narrow bandwidth. However, significant effort has been recently made to realize high performance antennas employing electromagnetic bandgap (EBG) structures printed on high permittivity substrates. In this paper, a novel high performance GPS patch antenna based on the fractal high-impedance surface EBG structure is described. Measurements show that the proposed GPS patch antenna offers good performance in terms of impedance and axial ratio (AR) bandwidth. Moreover, an improvement in terms of gain is obtained.

\section{The Fractal Hi-ImPedAnCE SURFACE GPS ANTENNA DESIGN}

A square patch antenna with one slit along the edge and one slot in the center, fed along the $45^{\circ}$ axis is shown in Fig. 1. Because the slit and slot provide perturbation, both the $\mathrm{TM}_{01}$ and

Manuscript received January 17, 2006; revised May 9, 2006.

The authors are with the Centre for Telecommunications Value-Chain Driven Research, School of Electronic and Communications Engineering, Dublin Institute of Technology, Dublin 8, Ireland.

Digital Object Identifier 10.1109/LAWP.2006.878900

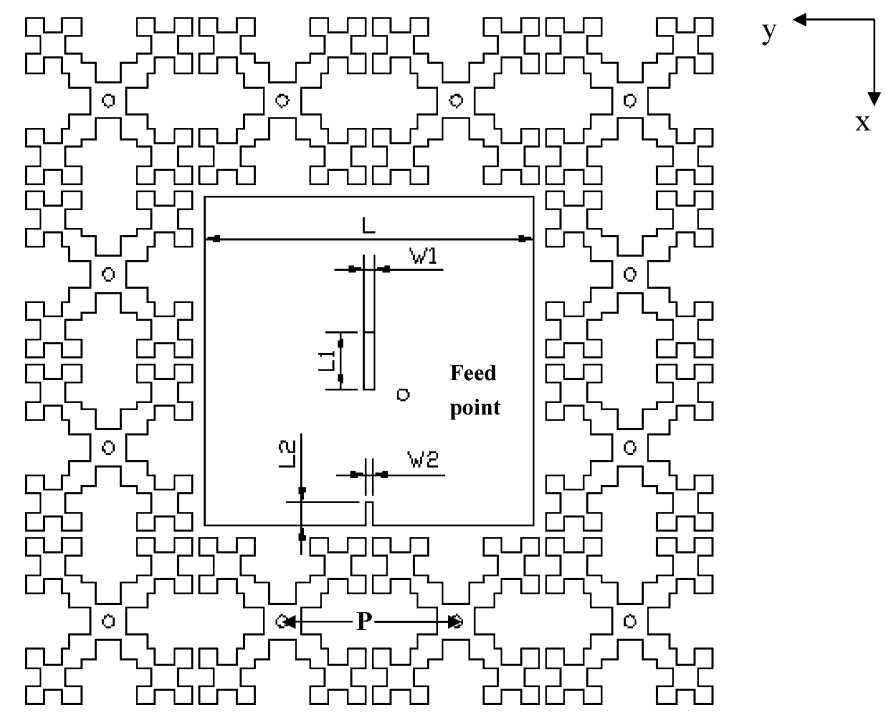

Fig. 1. Geometry of GPS patch antenna with the fractal EBG structure.

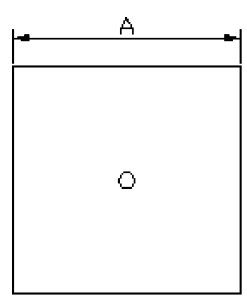

(a)

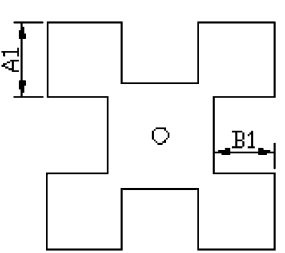

(b)

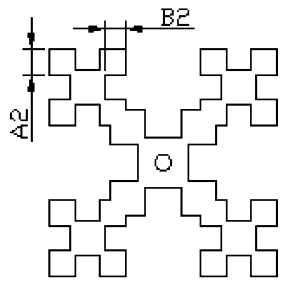

(c)
Fig. 2. Scheme of the fractal iteration structure. (a) 0th iteration; (b) 1 st iteration; (c) 2nd iteration.

$\mathrm{TM}_{10}$ orthogonal modes are excited, which produce circular polarization. The optimized dimensions of the patch antenna are: $L=27.8 \mathrm{~mm}, L 1=5 \mathrm{~mm}, W 1=1 \mathrm{~mm}, L 2=2 \mathrm{~mm}$, $W 2=0.6 \mathrm{~mm}$, the feeding point is along the diagonal, offset from the center of the square patch by $3.1 \mathrm{~mm}$. The substrate used is Rogers TMM10, which has a dielectric constant $\varepsilon_{r}=$ 10.2 , a thickness of $h=1.905 \mathrm{~mm}$ and the ground plane size is $80 \mathrm{~mm} \times 80 \mathrm{~mm}$. In general, because of surface waves, the gain of the conventional patch antenna on a high permittivity substrate is low and the bandwidth is very narrow. In contrast to that, the proposed fractal EBG enhanced GPS patch antenna shown in Fig. 1, yields higher gain and wider bandwidth thanks to the reduction of surface waves.

Fractal shapes have been reported to be a valid tool in antenna design and EBG applications to achieve larger bandwidth and easier design of the operating bandwidth [7]-[9]. This particular geometry can aid miniaturization of the structure and overall 


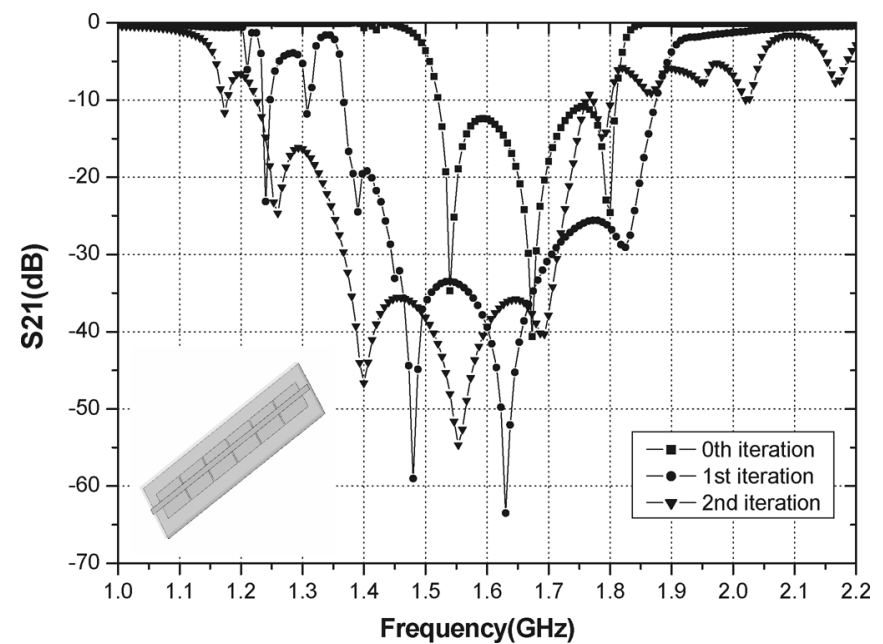

Fig. 3. Simulated results of S21 for 0th, 1st and 2nd iteration fractal EBG structure.

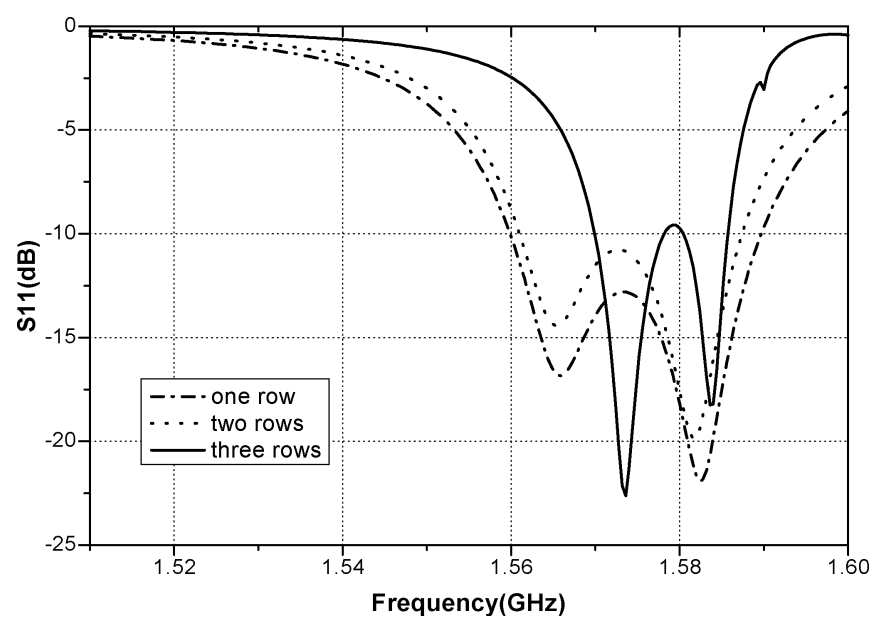

Fig. 4. Comparison of S11 for antennas with different rows of fractal EBG structure.

performance through multiple strategic resonant frequencies. In this paper, the fractal shapes are provided using the Minkowski loop generator. The initial shape is the square patch of side A (0th iteration). In the 1st and 2nd iteration, each side is replaced with new scaled generator $(\mathrm{A} 1=\mathrm{A} / 3 ; \mathrm{B} 1=4 / 5 \mathrm{~A} 1$, $\mathrm{A} 2=\mathrm{A} 1 / 3, \mathrm{~B} 2=4 / 5 \mathrm{~A} 2$ ), where $\mathrm{A} 1, \mathrm{~A} 2$ and $\mathrm{B} 1, \mathrm{~B} 2$ are, respectively, segment and indentation lengths shown in Fig. 2. The period $P$ of the proposed EBG structure is $15 \mathrm{~mm}, \mathrm{~A}=$ $14.4 \mathrm{~mm}, \mathrm{~A} 1=4.8 \mathrm{~mm}, \mathrm{~A} 2=1.6 \mathrm{~mm}, \mathrm{~B} 1=4.32 \mathrm{~mm}, \mathrm{~B} 2=$ $1.44 \mathrm{~mm}$. The inductive contribution to the surface impedance is increased by connecting each fractal patch to the continuous ground plane through a shorting pin with a radius of $0.5 \mathrm{~mm}$.

Fractal iterations from the zeroth to the second of the high-impedance surface are compared in terms of their simulated transmission characteristics obtained through a finite element method (FEM). In order to individuate the bandgap of the different structures treated, a $50 \Omega$ microstip is introduced above one row of 6 EBG cells and S21 is calculated across the transmission line (Fig. 3). The microstrip is separated from the EBG periodic structure by a $1.52 \mathrm{~mm}$ Rogers TMM10 layer. The frequency ranges where $|\mathrm{S} 21|$ is greater than $-10 \mathrm{~dB}$ is considered to be a bandgap as referred in [10]. From these

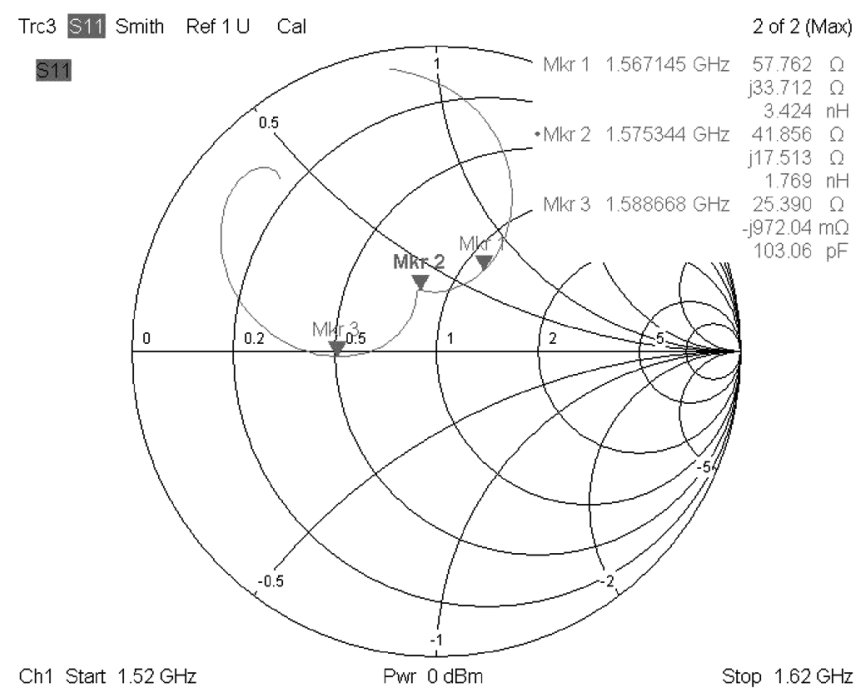

5/21/2005, 11:13 AM

(a)

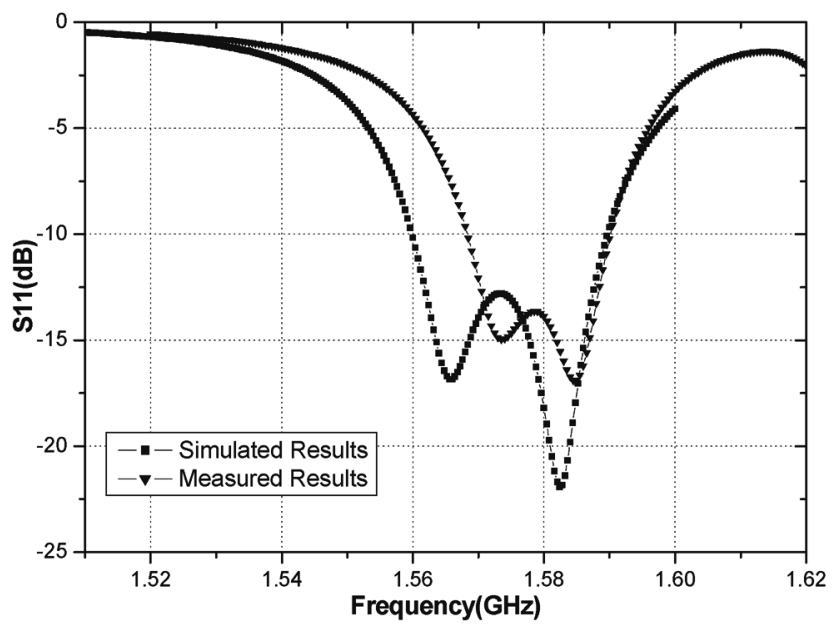

(b)

Fig. 5. Measurements and simulations of the GPS antenna with fractal hi-impedance surface. (a) S11 on Smith chart; (b) measured and simulated results of S11 on log-scale.

results illustrated in Fig. 3, the 2nd fractal EBG shows a wider bandstop than the 0th and the 1st iteration based shape. The structure based on the 2nd fractal iteration presents a bandgap between 1.22 and $1.76 \mathrm{GHz}$. Over this range of frequency the surface offers an S21 greater than $10 \mathrm{~dB}$. Moreover, due to the additional inductance introduced in the 2 nd fractal iteration, the center frequency of the bandstop is lower than the one observed for the 0th and the 1st iteration. This technique effectively leads to the miniaturization of the structure, if only by $10 \%$. In order to keep the overall dimensions of the antenna small, the number of EBG cells around the radiating element has to be designed in such a way to achieve the best compromise between compactness and performance. Different configurations of the EBG patch antennas with one, two and three rows of the EBG cells positioned all around the central patch are simulated. A comparison of the results shows that the bandwidth of the antenna decreases when the number of EBG cells increases 


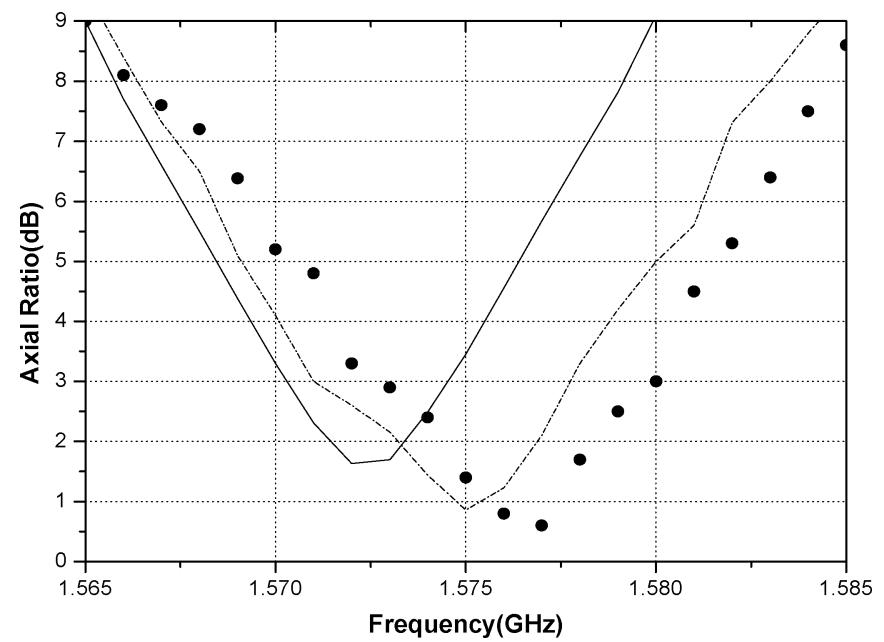

Fig. 6. The simulated and measured axial ratios in the broadside direction.

as displayed in Fig. 4. The decrease in bandwidth is mainly due to the increase in groundplane size, required in order to accommodate the extra EBG cells. The proposed design combines the benefit of EBG gain enhancement capability and a bandwidth-optimized groundplane size (i.e., $80 \mathrm{~mm} \times 80 \mathrm{~mm}$ ).

\section{Simulation AND MeAsurements}

Fig. 5 shows the return loss for the proposed EBG GPS antenna both on a Smith chart and in log-scale. Those plots show the return loss to be greater than $10 \mathrm{~dB}$ from $1566 \mathrm{MHz}$ to 1588 $\mathrm{MHz}$. The simulated and measured axial ratio in the broadside direction against frequency is shown in Fig. 6. From these results, the axial ratio bandwidth of the EBG antenna is found to be better than that of the same patch without EBG by $60 \%$ ( $3 \mathrm{MHz}$ ). The measured axial ratio is less than $3 \mathrm{~dB}$ from 1.571 to $1.580 \mathrm{MHz}$ for the optimized EBG antenna. Measured results show that the center frequency of $1.577 \mathrm{GHz}$ has a minimum axial ratio of about $0.60 \mathrm{~dB}$. Measured radiation patterns at $1.577 \mathrm{GHz}$ are shown in Fig. 7 for the XoZ and YoZ cuts, respectively. These patterns are normalized to the maximum value $(7.0 \mathrm{dBi})$ and have been obtained through a spinning dipole technique [11]. A very low axial ratio is measured in the upper half-plane radiation direction: 0.6 and $1.0 \mathrm{~dB}$, respectively, for the YoZ and the XoZ cut. In addition to that, a considerable improvement of $1.5 \mathrm{~dB}$ in terms of gain is obtained when compared to the same antenna without EBG.

\section{CONCLUSION}

A compact GPS patch antenna with an integrated fractal hi-impedance surface ground plane is presented.

It provides circular polarization with a good AR better than $3 \mathrm{~dB}$ within a reasonably wide frequency range, covering the L2 bandwidth of the GPS standard. A gain improvement of $1.5 \mathrm{~dB}$ and a $60 \%$ wider axial-ratio bandwidth is achieved in comparison with the same antenna without EBG.

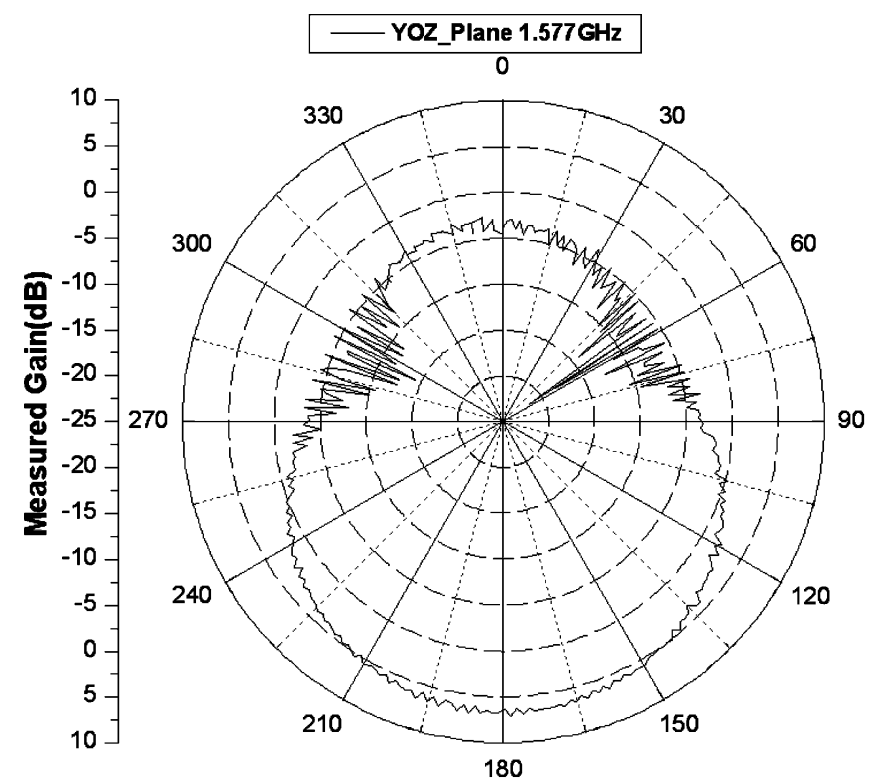

(a)

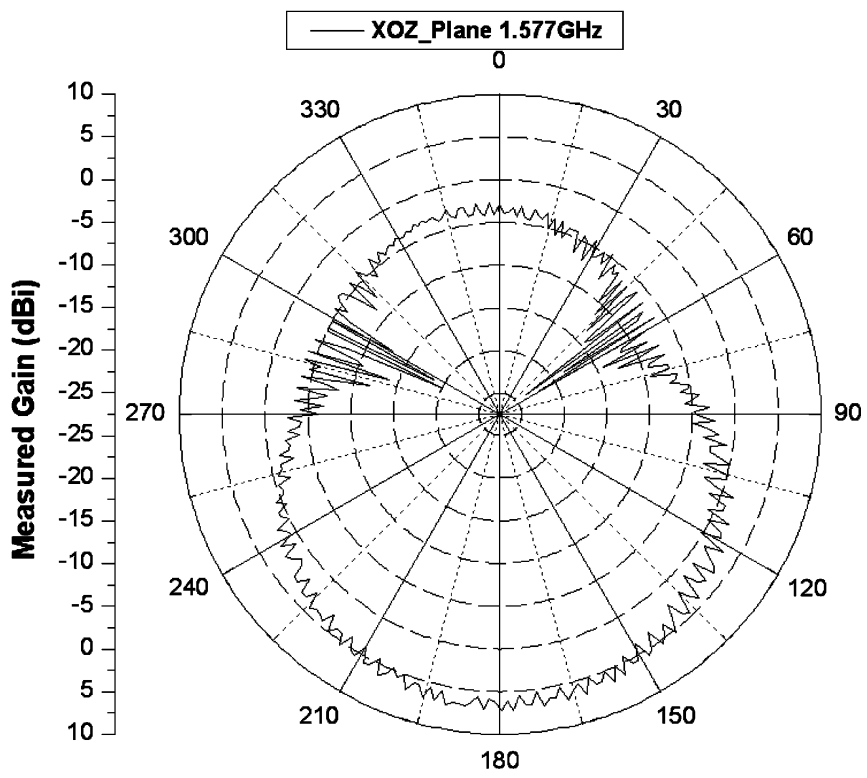

(b)

Fig. 7. Measured radiation patterns at $1.577 \mathrm{GHz}$. (a) radiation patterns for YoZ plane ( $5 \mathrm{~dB} /$ division); (b) radiation patterns for $\mathrm{XoZ}$ plane ( $5 \mathrm{~dB} /$ division $)$.

\section{REFERENCES}

[1] K.-L. Wong, Compact and Broadband Microstrip Antennas. New York: Wiley-InterScience, 2002.

[2] F. Yang and Y. Rahmat-Samii, "Curl antenna over electromagnetic band-gap surfaces: a low profiled design for CP application," in Proc. IEEE Antennas and Propagation Society Int. Symp., vol. 3, 2001, pp. 372-375.

[3] F. Ferrero, C. Luxey, G. Jacquemod, and R. Staraj, "Dual-band circularly polarized microstrip antenna for satellite applications," IEEE Antennas Wireless Propag. Lett., no. 4, pp. 13-15, 2005.

[4] J. Y. Park, C. C. Chang, Y. Qian, and T. Itoh, "An Improved low profile cavity-backed slot antenna loaded with 2D UC-PBG Refector," in Proc. IEEE Antennas and Propagation Society Int. Symp., 2001, pp. 194-197.

[5] M. Rahman and M. A. Stuchly, "Circularly polarized patch antenna with periodic structure," Proc. Inst. Elect. Eng. Microw. Antenna Propag., vol. 149, no. 3, pp. 141-146, Jun. 2002. 
[6] L. I. Basilio, J. T. Williams, D. R. Jackson, and M. A. Khayat, "A comparative study of a new GPS reduced-surface-wave antenna," IEEE Antennas Wireless Propag. Lett., no. 4, pp. 233-236, 2005.

[7] D. H. Werner and S. Ganguly, "An overview of fractal antenna engineering," IEEE Antennas Propag. Mag., vol. 45, no. 1, pp. 38-57, Feb. 2003.

[8] F. Frezza, L. Pajewski, and G. Schettini, "Fractal two-dimensional electromagnetic bandgap structures," IEEE Trans. Microw. Theory Techniques, vol. 52, no. 1, pp. 220-227, Jan. 2004.
[9] G. Goussetis, Y. Guo, A. P. Feresidis, and J. C. Vardaxoglou, "Miniaturised and multiband artificial magnetic conductors and electromagnetic band gap surfaces," Proc. IEEE Antennas and Propagation Society Int. Symp., vol. 1, pp. 20-25, 2004.

[10] V. Radisic, Y. Qian, R. Coccioli, and T. Itoh, "Novel 2-D photonic bandgap structure for microstrip lines," IEEE Microw. Guided Wave Lett., vol. 8, no. 2, pp. 69-71, 1998.

[11] A. C. Balanis, Antenna Theory Analysis and Design. New York: Wiley. 